\title{
AUDIO-TAPED EXPOSURE THERAPY IN A CASE OF OBSESSIONAL NEUROSIS*
}

\author{
BRUCE A. THYER \\ Department of Psychiatry, University of Michigan Hospitals \\ Ann Arbor, Michigan
}

\begin{abstract}
Summary-A patient-recorded audio-tape of intrusive ideation was employed as the anxiety evoking stimulus during the course of exposure therapy with an obsessional neurotic. Detailed records of the patient's subjective anxiety within and across treatment sessions documented the remission of self-reports of obsessional ideation. Treatment gains were maintained at 1 -year follow-up.
\end{abstract}

Prolonged real life exposure to anxiety evoking stimuli has been shown to be an effective treatment strategy for phobic disorders, compulsive rituals and certain sexual dysfunctions mediated by anxiety (Thyer, 1981, 1983; Marks, 1981). Such treatment requires accurately isolating the critical features of each patient's specific anxiety evoking stimuli and recreating such stimuli under controlled conditions, either within the clinician's office, or preferably, within more natural contexts (Thyer, 1985). This is usually feasible when the patient presents with specific fears of objects, animals or circumscribed situations, and with compulsive rituals evoked by environmental stimuli such as dirt or other contaminants. In the case of treating the patient with an obsessional disorder the clinician is faced with a somewhat more difficult problem in that the anxiety evoking stimuli are not features of the patient's external environment but private events, thoughts, images or impulses perceptible only to the patient.

The development of effective therapies for the purely obsessional patient has lagged behind that of treating the compulsive ritualizer. Neither the behavior therapies nor contempor- ary pharmacological approaches have yet been shown, in well designed controlled clinical trials, to exert specific anti-obsessional effects (Rachman and Hodgson, 1980; Marks, 1983). The following report illustrates the use of audio-taped exposure therapy in the treatment of a case of obsessional ideation.

\section{CASE HISTORY}

The patient was a 36-year-old white woman who came to the Anxiety Disorders Program complaining of pervasive fears of knives and other sharp objects such as scissors. Careful assessment revealed that the patient met the DSMIll criteria for obsessive-compulsive disorder (American Psychiatric Association, 1980). Two years earlier, she had read a true account of a man who had apparently run amok, murdering a number of people with an axe and then setting fire to his house, wherein he perished. She did not experience an abnormally troubled reaction upon initially reading this story. Several days later the patient was in her young daughter's bedroom repairing wall plaster with a sharp putty knife. As she stood over the bed, she recollected the murderous account read earlier and was suddenly seized with a morbid fear that someday she too would go insane and murder her family with a knife. This episode marked the heginning of subsequent daily, repetitive, intrusive thoughts and images of a highly disturbing nature, focused upon the theme of her suddenly losing control of her actions and stabbing her daughter. As a consequence she developed a morbid aversion to the sight or use of knives, and either discarded or hid from view all sharp household implements.

* Requests for reprints should be addressed to: Bruce A. Thyer, School of Social Work, Florida State University, Tallahassee, FL 32306, U.S.A. 
There was an apparent absence of any pre-morbid obsessive-compulsive symptomatology, psychosis or impulse control disorder. This pattern, however, of the sudden onset of a rull-blown obsession centered upon thoughts of violence has been recognized to occur with relative trequency in the etiology of obsessive-compulsive disorder (Blacker and Levitt, 1979). There was an absence of compulsive rituals such as checking or washing.

\section{Treatment}

Obsessions are known to be more resistant to behavioral treatment than overt compulsive rituals or avoidance behavior (Rachman and Hogson, 1980). Therefore, efforts first focused upon helping the client to overcome her fear of krives and other sharp objects through the use of standard real life exposure therapy (Thyer, 1981. 1983, 1985). Intially the patient's avoidance of knives was treated in the office, followed by explicit homework assignments for her to conduct independently in the natural environment. She would practice, for example, looking at and handling butcher knives (which were maximally anxieryprovoking) in the consulting room, aided by the therapist's modeling, encouragement and reassurance. Mutual visits were made to local cutlery shops where she asked the clerk to let her examine various sharp cutting tools. At home, she was instructed to take all her knives out of the drawer where she had hid them and to keep them stored in a clear glass container on the kitchen countertop. She was asked to resume the practice of cutting her daughter's naits with small scissors, and to periodically trim her bangs. In the latter stages of treatment, she was instructed to set up situations at home involving butcher knives and her daughter. For example. she would arrange to have the two of them prepare elaborate meals together with sharp knives casually laid on the countertop between them as they worked side by sicte. Extreme care was taken for the pariont to arrange these homework assignments as a part of natural mother-daughter interactions.

Formal treatment sessions were conducted bi-weekly and the patient's subjective fears of knives and overt avoidance behavior rapidly decreased during the 2 months of exposure therapy this entailed. However, obsessional ideation and imagery continued unabated, and she began to complain bitterly about their persistence. Accordingly, therapeutic attention was focused upon the obsessions per se. The patient was asked to write out a complete and detailed account of her intrusive thoughts and not to omit any unpleasant aspects. Previously she had expended a great deal of energy in suppressing her intrusive thoughts and images, and the four-page description she returned at the next appointment was the first time she had fully faced her obsessional scenario. She rehearsed reading the obsession a few times in front of the therapist (initially with tears and a tremulous voice), and then dictated it onto an audio cassette tape. Following the lead of Parkinson and Rachman (1980), her instructions were to listen privately to the tape 10 consecutive times per day and to record the maximum degree of anxiety she experienced upon hearing each repetition. She was irained in the use of Wolpe's subjective anxiety scale (1973) to quantify her obsessional fears $(0=$ complete calmness, $100=$ panic or terror $)$. This self-report measure is extensively employed as an outcome measure in behavioral research and therapy and is known to be associated with several measures of autonomic arousal (Thyer, Papsdort, Davis and Vallecorsa, 1984). Compliance with the above practicioner instigations was enhanced by having the patien read a selt-help manual describing the rationale and conduct of exposure therapy for anxiery disorders (Narks, 1978) and discussing any questions she may have had with the therapist.

\section{RESULTS}

Despite the extreme anxiety engendered upon listening to the recorded obsession, the patient reliably practiced her homework assignments. The results from the first 11 weeks of this program are presented in Fig. 1. The patient experienced near terror on the first day of homework practice while listening to the 10 repetitions of the obsessional tape. Anxiety appeared to decrease little, if any. Nevertheless, clinical improvements became apparent with repeated practice over time and by the end of 11 weeks she had reached a plateau, consistently reporting anxiety scores between zero and 10 points. No further decreases became apparent during weekly practice for an additional 2 weeks. By

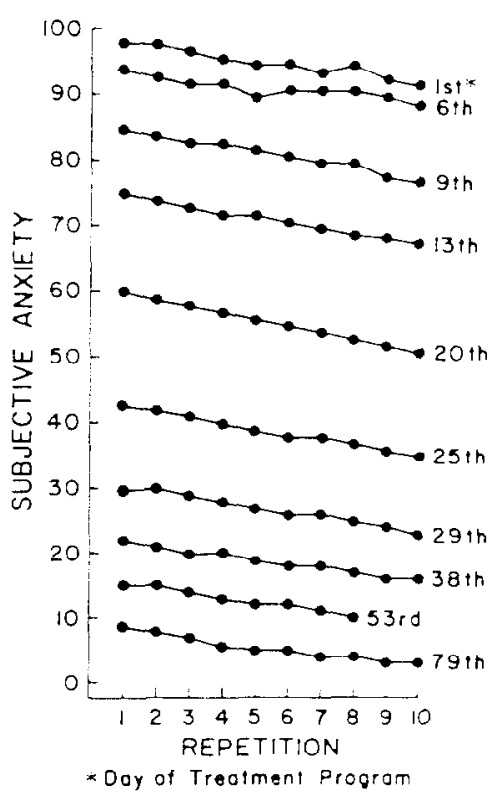

Fig. 1. The effects of satiation to instrusive ideation on subjective anxicty in an obsessional neurotic 
the end of the 50th day she was complaining that the tape was very boring and it was hard for her to endure a full 10 repetitions, not because of anxiety but because of tedium. On day 54 in fact, she quit listening to the tape after eight trials. Of greater clinical significance is that concurrent with the reduction of anxiety reported when listening to the obsessional tape, the patient noted that the frequency of spontaneous obsessional ideation greatly decreased, and that on their rare occurrences they no longer bothered her. At the conclusion of this program the patient was free of intrusive thoughts and images and comfortable using knives and other sharp objects around her daughter. Written correspondence from the patient 12 months after the termination of treatment indicated continued remission of obsessive-compulsive symptomatology.

\section{DISCUSSION}

This study suggests that conventional exposure therapy procedures may be effectively employed in treating obsessional neurosis, once the clinician develops a way to reproduce the patient's intrusive thoughts in a reliable manner. In the present case an audio-tape of the patient describing her obsession was employed. Alternatives may include having the patient read or overtly write out the obsessional scenario in complete detail.

In many clinical situations, such as the present study, the practitioner is unable to implement an experimental analysis of treatment effectiveness (Thomas, 1978). In these instances, empirically demonstrating that the client's presenting problem has indeed changed may then be a worthwhile compromise goal, even though the source of such changes may not be isolated. It is known that obessional neurosis has an extremely poor prognosis with respect to spontaneous remission (Kringlen, 1965 ) and the purely obsessional patient typically remains resistant to treatment (Rachman and Hodgson, 1980). These latter factors, coupled with the favorable results obtained in the present study, suggest that audio-taped exposure therapy is a worthwhile treatment option in the treatment of obsessional neurosis.

\section{REFERENCES}

American Psychiatric Association (1980) Diagnostic and Statistical Manual of Mental Disorders (3rd edn) American Psychiatric Association, Washington, DC.

Blacker K. and Levitt M. (1979) The differential diagnosis of obsessive-compulsive symptoms. Comp. Psychiat. 20, 532-547.

Kringlen E. (1965) Obsessional neurotics: A long-term follow-up. Brit. J. Psychiat. 111, 709-722.

Marks 1. M. (1978) Living with Fear. McGraw-Hill, New York.

Marks I. M. (1981) Cure and Care of Neurosis. Wiley, New York.

Marks I. M. (1983) Are there anticompulsive or antiphobic drugs? A review of the evidence. Br. J. Psychiat. 143, 338-347.

Parkinson L. and Rachman S. (1980) Are instrusive thoughts subject to habituation? Behav. Res. Ther. 18, 409-418.

Rachman S. and Hodysun R. (1980) Obsessions and Compulsions. Prentice-Hall, Englewood Cliffs.

Thomas E. J. (1978) Research and service in single-subject experimentation: Conflicts and choiccs. Soc. Wrk. Res. Abst. 14, 20-31.

Thyer B. A. (1981) Prolonged in vivo exposure therapy with a 70-year-old woman. J. Behav. Ther, \& Exp. Psychiat. 12, 69-71.

Thyer B. A. (1983) Treating anxiety disorders with exposure therapy. Soc. Casewrk. 64,77-82.

Thyer B. A. (1985) The treatment of phobias in their natural contexts. J. appl. Soc. Sci. 9, 73-83.

Thyer B. A., Papsdorf J. D., Davis R. and Vallecorsa S. (1984) Autonomic correlates of the subjective anxiety scale. J. Behav. Ther. \& Exp. Psychiat. 15:3-7.

Wolpe J. (1973) The Practice of Behavior Therapy (2nd edn). Pergamon Press, New York. 